\title{
Lifetime abstainers and mortality risk in the United States
}

\author{
Richard G. Rogers, Patrick M. Krueger, Richard Miech and \\ Elizabeth M. Lawrence*
}

\begin{abstract}
We examine variability in mortality risk among heterogeneous nondrinking statuses. We employ Cox proportional hazard models and the United States National Health Interview Survey-Linked Mortality Files (NHIS-LMF) to examine the risk of death associated with drinking and nondrinking statuses, net of demographic, socioeconomic, behavioural, health and geographic factors. Mortality risk is low for light drinkers and many individuals who abstain from drinking - including those who abstain for religious and moral reasons, have a responsibility to family, were brought up not to drink and are not social. Mortality is higher among former, infrequent and moderate drinkers, and among individuals who abstain because they do not like the taste of alcohol, are concerned that they will lose control or are concerned about adverse consequences. Unsurprisingly, mortality risk is by far the highest for heavy drinkers. Our results show that reasons for abstention capture heterogeneity in the risk of death among lifetime abstainers.
\end{abstract}

\section{Introduction: better understanding the relationship between drinking and mortality}

It is important to study the association between alcohol consumption and mortality because drinking contributes to differential longevity and is quite common in many parts of the world. In the United States in 2011, among adults aged 18 and over, $52 \%$ were current regular drinkers, $13 \%$ were current infrequent drinkers, $15 \%$ were former drinkers and $20 \%$ abstained from drinking (Schiller et al. 2012). Notably,

${ }^{*}$ Richard Rogers (correspondence author), Population Program, University of Colorado, USA.

Email: richard.rogers@ colorado.edu

Patrick M. Krueger, Department of Health and Behavioral Sciences, University of Colorado, USA.

Richard Miech, Survey Research Center, University of Michigan, USA.

Elizabeth M. Lawrence, Department of Sociology and Population Program, IBS, University of Colorado, USA. 
many researchers have focused on current drinkers but offer limited insight into the elevated mortality among lifetime abstainers. This study elucidates the heterogeneity in drinking statuses, especially abstaining and their relationship to mortality.

\subsection{Significance}

Many demographic studies of health and longevity have focused on such health behaviours as tobacco consumption, exercise and diets. Alcohol consumption is a major cause of death in many countries throughout the world. Indeed, it is the third most prevaelent preventable cause of death in the United States, trailing cigarette smoking and diet/inactivity, and contributing to 85,000 excess deaths in the year 2000 (Mokdad et al. 2004). Like smoking, excessive alcohol consumption affects a variety of organs and can have long latency periods that ultimately increase the risk of chronic alcoholism; chronic liver disease and cirrhosis of the liver; hypertensive heart disease; stroke; and cancers of the liver, mouth, larynx and pharynx, esophagus and female breast. It can also have more immediate mortal effects through such external causes as accidents, suicides and homicides (Himes 2011; Rehm et al. 2010).

The relationship between alcohol consumption and health and longevity is complex. Many studies have touted the benefits of light alcohol consumption, which can reduce the risk of heart disease, increase HDL cholesterol, reduce blood clotting, reduce inflammation and reduce stress and anxiety (Agarwal 2002; Beaglehole and Jackson 1992; Himes 2011). Furthermore, it is often associated with celebrations and can facilitate social intercourse. Studies of select populations have underscored the benefits of drinking. For example, Poulain and associates (2012) have shown that most areas with high concentrations of centenarians also have high prevalence rates of drinking. This finding could highlight the benefits of drinking to extreme longevity, or indicate selective survival of individuals who live in areas with high drinking rates and are hardy enough to tolerate alcohol.

Benefits notwithstanding, alcohol consumption can also harm health. Excessive alcohol consumption or alcohol abuse can reduce immune function, cause disability and hasten death. Alcohol abuse can contribute to conflict among family, friends and coworkers; stunt educational attainment; and lead to higher rates of unemployment, on-the-job accidents, lost promotions, lost jobs and failed marriages (Centers for Disease Control and Prevention [CDC] 2013).

Notably, little research has examined heterogeneity in the mortality outcomes of lifetime abstainers. Most literature reports a J-shaped relationship between drinking and mortality, with the nadir among light drinkers and higher mortality among nondrinkers and moderate to heavy drinkers (see Doll et al. 1994). We advance prior research by focusing on the diverse mortality outcomes among nondrinkers. Specifically, we distinguish lifetime abstainers from lifetime infrequent drinkers and former drinkers, and examine whether respondents' stated reasons for abstaining are associated with the risk of death. 


\subsection{Literature review}

A key concern with the J-shaped relationship of alcohol and mortality is that it obscures the heterogeneity among abstainers (those who have not consumed 12 drinks in their lives) — a key group of nondrinkers (Andreasson 1998). Abstainers differ in their reasons for abstention, the strength of their abstention convictions and their views on others' drinking (Graham 1998; Hilton 1986). Further, a variety of factors that influence attitudes toward abstention, including normative and cultural contexts (Bernards et al. 2009), may also influence the risk of death. Some abstainers may live in areas where the sale of alcohol is legally prohibited, belong to religions that oppose drinking or have friends and family members who also abstain.

Thus, to better determine the ways abstainers may differ in their risk of death, we focus on the reasons for their abstention. Though the reported reasons do not necessarily reflect causal paths to abstention, the reasons should reflect some value or attitude in which abstention is rooted (Hilton 1986). Some abstainers may point to beneficial forces in their lives that promote abstention, while others may identify reasons that suggest less positive motivations. Differentiating abstainers through these reasons may thus provide information on additional influences that affect drinking and mortality and clarify the J-shaped relationship.

Another limitation of the research on nondrinking and mortality is that few studies adjust for the myriad characteristics that differ between nondrinkers and drinkers, including detailed demographic, health, health behaviour, socio-economic and geographic confounders Andreasson 1998; Graham 1998). One important confounding influence is health. As put forth by Shaper and associates (1988), the sick-quitter hypothesis attributes the disproportionate rates of sick individuals in nondrinker and infrequent drinker categories to the fact that individuals often change drinking statuses when their health becomes poor. Supporting this hypothesis, those who receive medical diagnoses or have declining health status are more likely to stop or reduce drinking (Liang and Chikritzhs 2010). To address this bias, studies now separate lifelong abstainers from former drinkers in analyses, but have had mixed results in determining whether lifelong abstainers have higher mortality risk than light or moderate drinkers, with some studies finding similar risks for both groups and others confirming a higher risk for abstainers (Fillmore et al. 2006; Klatsky 2001; Wannamethee and Shaper 1997). Part of the reason for the mixed results may be that researchers have not fully adjusted for health among lifetime abstainers.

To limit the confounding effects of background factors on mortality risk, we adjust for a variety of demographic, socio-economic, social, behavioural, health and geographic controls. Drinking is more common among males than females (Himes 2011; Rosenquist et al. 2010; Schiller et al. 2012). Also, the prevalence of current regular drinking in the United States in 2011 declined with age, from 57\% among adults aged $18-44$ to $41 \%$ among those $65-74$ and just $30 \%$ among those aged 75 and above (Schiller et al. 2012). And drinking statuses vary substantially by race/ethnicity. For example, Asian Americans are much more likely than other major race/ethnic groups to be lifetime abstainers (Schiller et al. 2012). 
Drinking status, including abstention, varies by marital status. Rosenquist et al (2010) found that individuals were more likely to abstain from drinking if their spouses abstained from drinking, and to drink heavily if their spouses drank heavily as well. A wife's abstention increased the likelihood that the husband abstained by $74 \%$, and a husband's abstention increased the likelihood that the wife abstained by $56 \%$. Because alcohol consumption correlates with other risky behaviours, we control for cigarette smoking and body mass (Falk et al. 2006; Lourenco et al. 2012).

It is important to use nationally representative data in empirical analyses of the association between alcohol consumption and mortality because substantial variation in alcohol consumption across US regions makes regional studies unlikely to generalise to the United States as a whole. US alcohol consumption has a rich and checkered history. National Prohibition, which lasted from 1920 to 1933, outlawed the manufacture, distribution and sale of alcohol (Blocker 2006). During the early part of the 20th century, other countries have adopted similar large-scale prohibition, including Canada, Finland and Norway (Blocker 2006). Even with the repeal of National Prohibition in the United States, many administrative units, including counties and towns, passed laws prohibiting or restricting the sale of alcohol (often called blue laws). Some of these restrictions are still in place or were eliminated only recently (Campbell et al. 2009). Further, many religious faiths oppose alcohol consumption, not only for their followers but for the larger community. Conversely, other religious groups use sacramental wine in their communions, and some monasteries are well known for their production of beer and wine.

\subsection{Our contribution}

We use a large nationally representative prospective data set to address two questions: (1) do specific, self-reported reasons for abstaining from drinking inform the alcohol/mortality relationship? And (2) how much of the relationship between abstaining and mortality is affected by other covariates?

This study builds on a parallel article examining the risk of death of nondrinkers (Rogers et al. 2013) that uses Latent Class Analysis to categorise different nondrinker statuses. While innovative, a tradeoff of the Latent Class Analysis used in the prior article is that it sacrificed information on specific reasons for nondrinking. In contrast, the present study spotlights the primary reasons for not drinking reported by lifelong abstainers, examining the relationship between these primary reasons and mortality while considering confounding influences. Therefore, this study provides an alternative coding scheme by more directly examining the primary reason why lifelong abstainers do not drink. 


\section{Data and methods}

\subsection{Data}

We use the 1988 NHIS-Alcohol supplement. This dataset is especially suitable for our analyses because it offers detailed information on drinking statuses and reasons for not drinking and can be linked to mortality through the National Death Index (NDI) Linked Mortality Files. The dataset provides mortality status updated through 2006, for an 18-year follow-up period.

We examine adults who are of legal drinking age (ages 21 and above). Although many younger individuals do drink, they cannot drink in public (including bars and restaurants) and can be arrested for underage drinking. Any additional risk of death could be due to either their drinking or their propensity toward illegal behaviour. Thus, we focus on legal drinking, reducing our sample size from the 43,379 individuals who completed the alcohol supplement and have a valid mortality status to 41,308.

\subsection{Methods}

\section{Drinking status and mortality}

We assess the risk of death by following individuals from their 1988 interviews to their date of death or the end of the follow-up period, 31 December 2006.

Because drinking status is the main independent variable, we provide as much detail as possible, especially among abstainers. We define abstainers as those who report they have not had 12 drinks in their lives, infrequent drinkers as those who have never had more than 12 drinks in any one year, former drinkers as those who have had 12 drinks in a year but not in the past year, and current drinkers as those who have had at least 12 drinks in the last year. Because the risk of death varies according to the frequency and quantity of alcohol consumption, we categorise current drinkers using a volume measure that multiplies the number of days the respondent reported drinking in the past year by the number of drinks consumed per drinking occasion, divided by 366 (because 1988 was a leap year). The resulting categories are less than 1 drink per day (referent), 1 to less than 2 drinks, 2 to less than 3 drinks, 3 or more drinks per day, and unknown number or frequency. One drink typically contains 12 grams of alcohol in the form of 1.5 ounces of 80 proof distilled spirits, 5 ounces of wine with $12 \%$ alcohol or 12 ounces of beer (USDHHS 2010).

We categorise abstainers according to their reported reasons for not drinking. In addition to 'other' and 'don't know', the NHIS provides 14 different reasons to abstain from drinking: (1) don't socialise very much, (2) don't care for it or dislike it, (3) am an alcoholic, (4) thought I might become an alcoholic, (5) had problems with drinking, (6) have a responsibility to my family, (7) family member an alcoholic or problem drinker, (8) medical or health reasons, (9) religious or moral reasons, (10) brought up not to drink, (11) makes me sick, (12) can't control my drinking, 
(13) costs too much or can't afford it, and (14) dieting or too fattening. Although respondents could identify multiple reasons, they were asked to identify the primary reason for not drinking, which is what we focus on in the analyses. Because of small samples and to reduce the complexity of interpretation, we combine some categories, in line with other literature looking at types of abstainers (Epler et al. 2009). 'Loss of control' includes the following individual reasons: am an alcoholic, thought I might become an alcoholic, had problems with drinking, family member an alcoholic or problem drinker, and can't control my drinking. 'Adverse consequences' combines medical or health reasons, makes me sick, costs too much, and dieting or too fattening. Thus, we have 8 major categories within the abstainer drinking status: religious or moral reasons, responsibility to family, not social, brought up not to drink, does not like, adverse consequences, loss of control, and unknown or other.

Our research, like most studies on the association between drinking and mortality, is based on self-reported drinking status. Some individuals may misreport their levels of consumption, providing more socially desirable answers that adhere to religious practices, cultural norms or community regulations. Fortunately, self-reported alcohol consumption information is considered reliable and valid (see Del Boca and Darkes 2003).

\section{Covariates}

We also control for important demographic, socio-economic, behavioural, health and geographic covariates. We control for sex (with male as the referent); race/ethnicity (non-Hispanic white [referent], non-Hispanic black, non-Hispanic Asian, Hispanic and other); smoking status (never smoked [referent], former smoker and current smoker); and marital status (married [referent], widowed, divorced or separated, and never married). A continuous indicator of years of educational attainment and logged US dollars of total household income capture socio-economic status. BMI and a squared indicator of BMI represent the nonlinear relationship between BMI and mortality. Region includes the four major Census regions of the country: the Northeast (referent), Midwest, South and West. The survival analyses we employ control for age implicitly, as age is used as the time variable.

Because health is associated with drinking statuses (Shaper et al. 1988) and mortality (Jylhä 2011), we also estimate models that exclude those who are in poor or fair self-rated health (SRH) status. SRH status includes five categories: poor, fair, good, very good and excellent. To directly address the sick-quitter hypothesis (Shaper et al. 1988) - that some individuals quit drinking or, in the case of lifetime abstainers, never start drinking because of poor health-we restrict the final model in Table 3 to those individuals who report good or better SRH status. 


\section{Cox proportional hazards models}

We use Cox proportional hazard models to examine drinking status, with a focus on abstention, and the risk of death. As is recommended by the National Center for Health Statistics [NCHS] (Massey et al. 1989), our models incorporate sample weights and account for the stratified and clustered sampling design through the 'svyset' commands in Stata (Statacorp 2011), adjusting for primary sampling units, strata and probability weights. Multiple imputation using the mi command in Stata 12.0 (Statacorp 2011) estimates values for alcohol consumption volume, education, income, smoking status, marital status and BMI. Multiple imputation allows us to preserve information from all cases while assuming that data are missing at random, conditional on observed variables, a weaker (i.e. more plausible) assumption than employed by listwise deletion (Allison 2002). We impute $2.5 \%$ of the independent variable of interest, as 1,051 of the 41,308 respondents were missing either frequency or number of days of consumption.

\section{Results}

Table 1 displays descriptive statistics of drinking status (the rows sum to approximately 100\%). Abstainers are more common among females than males, non-Hispanic Asians than other race/ethnic groups, older rather than younger adults, never- rather than ever-smokers, widowed persons rather than those with other marital statuses, individuals with lower rather than higher levels of education, individuals with lower rather than higher incomes and individuals at the BMI extremes (either underweight or obese) rather than those of normal weight; they are also more common in the south than in other regions of the country. Furthermore, compared to other drinking statuses, abstainers are more likely to report fair or poor health status.

Table 2 shows the distributions of the reasons individuals abstain from drinking across our covariates (the rows sum to about $100 \%$ ). For example, among never smokers, $23 \%$ of abstainers abstain for religious and moral reasons, $13 \%$ because they were brought up not to drink, $48 \%$ because they do not like the taste of alcohol and $5 \%$ because of concerns about adverse consequences. Respondents who do not drink because they do not like the taste are the largest group, comprising about half of abstainers, though those abstaining for religious or moral reasons are also a sizable group that makes up about one-third of the abstainers. Reasons for abstention vary across the social and demographic variables. For example, the oldest adults, those 65 and over, show a disproportionately higher percentage of being brought up not to drink, but, as might be expected, a disproportionately lower percentage reporting responsibility to family as the primary reason for abstention. Fewer Hispanics abstain for religious or moral reasons, but more abstain because they do not like the taste. Because the association between drinking status and the other covariates warrant an examination of drinking status and mortality within a multivariate framework, we turn to Table 3. 
Table 1:

Descriptive statistics of drinking status, US adults aged 21 and above, 1988

\begin{tabular}{|c|c|c|c|c|c|c|c|}
\hline & \multicolumn{7}{|c|}{ Drinking status } \\
\hline & \multirow[b]{2}{*}{ 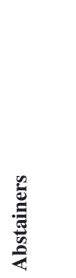 } & \multirow[b]{2}{*}{ 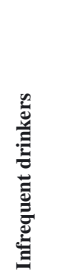 } & \multirow[b]{2}{*}{ 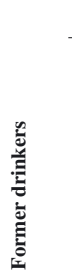 } & \multicolumn{4}{|c|}{ Current Drinkers } \\
\hline & & & & 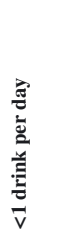 & 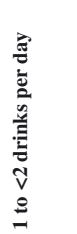 & 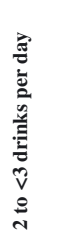 & 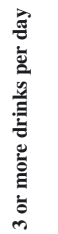 \\
\hline \multicolumn{8}{|l|}{ Sex } \\
\hline Male & $9.3 \%$ & $6.3 \%$ & $19.6 \%$ & $42.8 \%$ & $12.6 \%$ & $4.6 \%$ & $4.9 \%$ \\
\hline Female & 25.0 & 15.6 & 18.1 & 35.7 & 4.2 & 1.0 & 0.6 \\
\hline \multicolumn{8}{|l|}{ Race/ethnicity } \\
\hline Non-Hispanic white & 15.4 & 10.7 & 18.1 & 41.5 & 8.7 & 2.9 & 2.8 \\
\hline Non-Hispanic black & 26.5 & 14.5 & 17.6 & 31.2 & 6.1 & 1.8 & 2.2 \\
\hline Hispanic & 26.7 & 14.6 & 12.2 & 34.9 & 7.3 & 2.2 & 2.1 \\
\hline Non-Hispanic Asian & 51.9 & 12.1 & 8.4 & 23.1 & 2.4 & 1.0 & 1.1 \\
\hline Other & 20.4 & 13.9 & 34.9 & 27.4 & 2.1 & 0.7 & 0.6 \\
\hline \multicolumn{8}{|l|}{ Age } \\
\hline $21-44$ & 13.2 & 9.1 & 16.1 & 47.0 & 9.1 & 2.8 & 2.7 \\
\hline $45-64$ & 17.6 & 12.9 & 21.8 & 34.5 & 7.5 & 2.8 & 2.9 \\
\hline $65+$ & 32.6 & 16.4 & 22.1 & 21.5 & 4.6 & 1.4 & 1.4 \\
\hline \multicolumn{8}{|l|}{ Smoking status } \\
\hline Never & 30.4 & 14.2 & 14.2 & 34.5 & 4.7 & 1.2 & 0.9 \\
\hline former & 7.3 & 9.4 & 26.5 & 42.1 & 9.6 & 2.9 & 2.2 \\
\hline Current & 7.7 & 9.1 & 19.5 & 42.8 & 11.4 & 4.4 & 5.2 \\
\hline \multicolumn{8}{|l|}{ Marital status } \\
\hline Married & 16.5 & 11.4 & 20.6 & 39.8 & 7.2 & 2.2 & 2.2 \\
\hline Widowed & 37.7 & 18.1 & 19.2 & 19.3 & 3.3 & 1.3 & 1.1 \\
\hline Divorced/separated & 12.4 & 10.8 & 19.3 & 41.9 & 9.2 & 2.8 & 3.6 \\
\hline Never married & 15.5 & 8.0 & 11.5 & 46.0 & 11.7 & 4.0 & 3.4 \\
\hline \multicolumn{8}{|l|}{ Education } \\
\hline Less than high school & 30.4 & 15.3 & 21.5 & 22.9 & 4.9 & 1.8 & 3.2 \\
\hline High school graduate & 17.3 & 12.3 & 19.7 & 37.7 & 7.6 & 2.6 & 2.8 \\
\hline Some college & 13.3 & 9.5 & 18.1 & 44.4 & 9.4 & 3.2 & 2.2 \\
\hline College graduate & 11.6 & 8.4 & 14.3 & 51.1 & 10.5 & 2.7 & 1.4 \\
\hline Postgraduate & 11.0 & 7.6 & 15.1 & 53.7 & 8.8 & 2.4 & 1.4 \\
\hline \multicolumn{8}{|l|}{ Income } \\
\hline$<\$ 10,000$ & 30.8 & 13.9 & 18.8 & 25.5 & 6.1 & 2.3 & 2.7 \\
\hline$\$ 10,000-\$ 19,999$ & 19.6 & 12.5 & 21.5 & 33.6 & 7.0 & 2.6 & 3.1 \\
\hline$\$ 20,000-\$ 29,999$ & 14.6 & 11.3 & 19.3 & 41.3 & 8.2 & 2.9 & 2.4 \\
\hline$\$ 30,000-\$ 39,999$ & 13.3 & 9.9 & 19.2 & 43.8 & 8.7 & 2.4 & 2.7 \\
\hline$\$ 40,000-\$ 49,999$ & 10.7 & 9.7 & 17.3 & 48.5 & 9.0 & 2.7 & 2.1 \\
\hline$\$ 50,000+$ & 16.8 & 11.0 & 16.2 & 43.4 & 8.4 & 2.4 & 1.9 \\
\hline \multicolumn{8}{|l|}{ BMI } \\
\hline Underweight & 23.0 & 13.4 & 17.6 & 37.5 & 5.0 & 2.1 & 1.3 \\
\hline Normal weight & 17.2 & 11.1 & 17.2 & 41.6 & 8.1 & 2.5 & 2.3 \\
\hline Overweight & 17.8 & 10.9 & 19.4 & 37.3 & 8.7 & 2.9 & 3.0 \\
\hline Obese & 21.9 & 14.4 & 23.6 & 30.6 & 5.3 & 2.0 & 2.3 \\
\hline \multicolumn{8}{|l|}{ Region } \\
\hline Northeast & 15.1 & 12.4 & 17.0 & 41.8 & 8.7 & 2.5 & 2.5 \\
\hline Midwest & 14.2 & 11.4 & 19.8 & 41.8 & 7.6 & 2.6 & 2.7 \\
\hline South & 25.1 & 12.2 & 19.0 & 32.7 & 6.7 & 2.1 & 2.3 \\
\hline West & 14.6 & 9.8 & 18.7 & 42.0 & 9.1 & 3.1 & 2.6 \\
\hline \multicolumn{8}{|l|}{ Health status } \\
\hline Good, very good or excellent & 16.6 & 11.0 & 17.5 & 41.5 & 8.3 & 2.6 & 2.4 \\
\hline Poor or fair & 28.4 & 15.2 & 26.4 & 20.4 & 4.8 & 2.0 & 2.8 \\
\hline $\mathrm{N}$ & 7859 & 4907 & 7794 & 15092 & 2842 & 839 & 1975 \\
\hline
\end{tabular}

Note: Adjusted for complex sampling frame. 'Other' for race contains cases that reported race as missing. Percentages may not add exactly to $100 \%$ because of rounding. $N=41308$.

Source: 1988 National Health Interview Survey Alcohol Supplement Linked Mortality File. 
Table 2:

Descriptive statistics of drinking status, US adults aged 21 and above, 1988

\begin{tabular}{|c|c|c|c|c|c|c|c|c|}
\hline & \multicolumn{8}{|c|}{ Primary reason for abstention } \\
\hline & 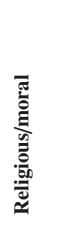 & 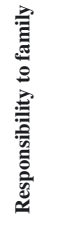 & 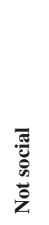 & 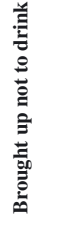 & 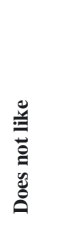 & 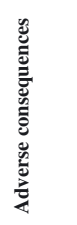 & 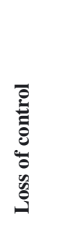 & 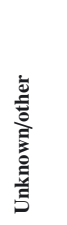 \\
\hline \multicolumn{9}{|l|}{ Sex } \\
\hline Male & $21.5 \%$ & $2.2 \%$ & $1.7 \%$ & $\% 10.7 \%$ & $47.4 \%$ & $6.7 \%$ & $2.9 \%$ & $6.9 \%$ \\
\hline Female & 20.5 & 1.6 & 0.9 & 12.8 & 51.0 & 5.2 & 3.2 & 4.8 \\
\hline \multicolumn{9}{|l|}{ Race/ethnicity } \\
\hline Non-Hispanic white & 24.9 & 1.7 & 0.9 & 14.3 & 48.4 & 5.1 & 3.4 & 1.3 \\
\hline Non-Hispanic black & 14.0 & 1.8 & 1.2 & 10.3 & 62.6 & 5.2 & 3.5 & 1.3 \\
\hline Hispanic & 8.5 & 2.7 & 2.1 & 6.7 & 68.8 & 6.7 & 3.2 & 1.4 \\
\hline Non-Hispanic Asian & 18.5 & 1.8 & 1.3 & 11.3 & 51.6 & 10.9 & 0.5 & 4.0 \\
\hline Other & 13.8 & 1.4 & 0.5 & 7.5 & 20.3 & 4.3 & 2.4 & 49.7 \\
\hline \multicolumn{9}{|l|}{ Age } \\
\hline $21-44$ & 21.8 & 2.7 & 1.3 & 8.9 & 50.5 & 6.3 & 3.7 & 4.8 \\
\hline $45-64$ & 24.8 & 1.6 & 0.9 & 10.6 & 48.3 & 5.5 & 2.5 & 4.9 \\
\hline $65+$ & 16.7 & 0.9 & 0.8 & 17.3 & 51.3 & 4.7 & 2.3 & 6.0 \\
\hline \multicolumn{9}{|l|}{ Smoking status } \\
\hline Never & 23.2 & 1.6 & 1.0 & 13.4 & 48.2 & 5.0 & 2.7 & 4.9 \\
\hline Former & 15.5 & 2.4 & 1.1 & 8.9 & 54.0 & 7.7 & 4.0 & 6.5 \\
\hline Current & 8.9 & 2.6 & 1.3 & 8.6 & 60.3 & 7.2 & 5.2 & 5.9 \\
\hline \multicolumn{9}{|l|}{ Marital status } \\
\hline Married & 25.2 & 2.5 & 0.7 & 11.0 & 48.2 & 4.9 & 2.7 & 4.8 \\
\hline Widowed & 16.2 & 0.6 & 0.8 & 17.8 & 50.9 & 4.4 & 3.2 & 6.1 \\
\hline Divorced/separated & 13.6 & 1.3 & 1.2 & 8.4 & 58.0 & 6.3 & 5.5 & 5.7 \\
\hline Never married & 17.2 & 1.4 & 2.4 & 10.7 & 51.0 & 9.0 & 3.0 & 5.2 \\
\hline \multicolumn{9}{|l|}{ Education } \\
\hline Less than high school & 13.5 & 1.6 & 1.3 & 13.8 & 55.7 & 5.5 & 3.2 & 5.4 \\
\hline High school graduate & 20.9 & 1.7 & 1.0 & 11.7 & 50.9 & 4.9 & 3.9 & 5.0 \\
\hline Some college & 28.7 & 2.0 & 0.7 & 10.9 & 44.8 & 4.9 & 2.6 & 5.3 \\
\hline College graduate & 30.1 & 1.7 & 0.9 & 13.3 & 39.0 & 8.2 & 1.5 & 5.2 \\
\hline Postgraduate & 34.2 & 2.5 & 1.0 & 9.2 & 38.4 & 7.8 & 2.0 & 5.0 \\
\hline \multicolumn{9}{|l|}{ Income } \\
\hline$<\$ 10,000$ & 15.3 & 1.7 & 1.1 & 14.0 & 53.4 & 6.4 & 3.9 & 4.3 \\
\hline$\$ 10,000-\$ 19,999$ & 20.8 & 1.8 & 1.6 & 13.7 & 48.9 & 5.6 & 3.0 & 4.5 \\
\hline$\$ 20,000-\$ 29,999$ & 25.6 & 2.5 & 0.5 & 12.2 & 46.2 & 4.8 & 2.5 & 5.7 \\
\hline$\$ 30,000-\$ 39,999$ & 29.7 & 1.5 & 0.8 & 9.3 & 46.7 & 5.1 & 2.8 & 4.1 \\
\hline$\$ 40,000-\$ 49,999$ & 27.0 & 2.3 & 0.8 & 10.5 & 45.9 & 4.3 & 2.3 & 6.8 \\
\hline$\$ 50,000+$ & 18.7 & 1.2 & 1.0 & 10.8 & 52.9 & 5.3 & 3.2 & 6.9 \\
\hline \multicolumn{9}{|l|}{ BMI } \\
\hline Underweight & 17.8 & 1.7 & 0.6 & 13.4 & 47.0 & 9.2 & 4.2 & 6.1 \\
\hline Normal weight & 21.3 & 1.7 & 1.2 & 12.6 & 48.8 & 5.9 & 3.0 & 5.4 \\
\hline Overweight & 20.9 & 1.6 & 0.9 & 12.3 & 51.4 & 5.2 & 2.8 & 4.9 \\
\hline Obese & 19.2 & 2.1 & 0.9 & 11.3 & 53.6 & 3.8 & 4.2 & 5.0 \\
\hline \multicolumn{9}{|l|}{ Region } \\
\hline Northeast & 13.4 & 1.8 & 1.7 & 11.3 & 57.7 & 6.5 & 2.3 & 5.3 \\
\hline Midwest & 21.5 & 1.4 & 1.2 & 15.2 & 44.3 & 6.1 & 4.7 & 5.6 \\
\hline South & 21.2 & 1.8 & 0.6 & 12.9 & 51.6 & 4.1 & 3.2 & 4.7 \\
\hline West & 26.2 & 2.1 & 1.4 & 8.4 & 45.5 & 7.8 & 2.2 & 6.4 \\
\hline \multicolumn{9}{|l|}{ Health status } \\
\hline Good, very good or excellent & 22.1 & 1.9 & 1.1 & 12.3 & 49.4 & 5.0 & 3.1 & 5.1 \\
\hline Poor or fair & 15.5 & 1.4 & 0.8 & 12.4 & 53.4 & 7.5 & 3.4 & 5.7 \\
\hline $\mathrm{N}$ & 1602 & 139 & 79 & 972 & 3997 & 421 & 243 & 406 \\
\hline
\end{tabular}

Note: Adjusted for complex sampling frame. 'Other' for race contains cases that reported race as missing. Percentages may not add exactly to $100 \%$ because of rounding.

Source: 1988 National Health Interview Survey Alcohol Supplement Linked Mortality File.

Table 3 shows the risk of death for persons with various drinking statuses, relative to current drinkers who drink less than one drink per day. Model 1 shows that 
the risk of death is similar for many abstainers and current light drinkers, given controls for sex and race/ethnicity. For example, compared to current drinkers who drink less than one drink per day, there is no statistically significant difference in mortality risk among individuals who abstain for religious or moral reasons $(\mathrm{HR}=0.94)$, out of responsibility to family $(\mathrm{HR}=0.90)$, because they are not social $(\mathrm{HR}=0.99)$, or because they were brought up not to drink $(\mathrm{HR}=1.06)$. But some abstainers have elevated risks of death. Compared to light drinkers, those who do not like the taste of alcohol $(\mathrm{HR}=1.16)$, abstain because they anticipate adverse consequences from drinking $(H R=1.30)$ or abstain because they fear losing control over their drinking $(\mathrm{HR}=1.42)$ have increased risks of death over the follow-up period. Compared to current light drinkers, infrequent, former, and moderate and heavy drinkers experience increased risk of death over the follow-up period. For example, current drinkers who drink 1 to less than 2 drinks per day have $18 \%$ higher risk of death, those who drink 2 to less than 3 drinks per day have $63 \%$ higher risk and those who drink 3 or more drinks per day have over twice the risk over the follow-up period.

Because current drinkers are more likely to smoke than nondrinkers (see Table 1), and because smoking increases the risk of death, controlling for smoking status increases the hazard ratios of each abstainer category and decreases the hazard ratios of the current drinker categories (Model 2). Thus, controlling for smoking reveals significant differences between light drinkers and those who abstain for moral or religious reasons $(\mathrm{HR}=1.15)$ or because they were brought up not to drink $(\mathrm{HR}=1.25)$. Adding controls for marital status (Model 3) does not appreciably change the drinking status hazard ratios for drinkers or abstainers. However, controlling for socio-economic status (education and income) reduces the hazard ratios for each abstainer category. Controlling for BMI (Model 5) ${ }^{1}$ and region (Model 6) does not substantially affect the drinking status hazard ratios.

The literature has documented that some former drinkers quit drinking because of previous health problems and that some abstainers avoid alcohol consumption because of pre-existing health conditions. As a test of the 'sick-quitter' hypothesis, in Model 7 we restrict the sample to individuals who are in good or better health. This restriction further reduces the hazard ratios among abstainers and former drinkers, although the results are substantively similar.

\footnotetext{
1 The squared BMI term has very large values, which contributes to the small (HR $=1.0004$ in Model 5) but statistically significant curvilinear relationship with mortality.
} 
Table 3:

Drinking status and the risk of death (hazard ratios), US adults aged 21 and above, 1988-2006

\begin{tabular}{|c|c|c|c|c|c|c|c|}
\hline & Model 1 & Model 2 & Model 3 & Model 4 & Model 5 & Model 6 & Model $7^{\mathrm{a}}$ \\
\hline \multicolumn{8}{|c|}{ Drinking status (current drinker, $<1$ drink/day) } \\
\hline \multicolumn{8}{|c|}{ Abstainers } \\
\hline Religious/moral & 0.94 & $1.15^{* *}$ & $1.16^{* *}$ & 1.06 & 1.06 & 1.05 & 0.99 \\
\hline Responsibility to family & 0.90 & 1.05 & 1.12 & 1.01 & 1.00 & 0.99 & 0.80 \\
\hline Not social & 0.99 & 1.19 & 1.17 & 1.05 & 1.05 & 1.05 & 0.93 \\
\hline Brought up not to drink & 1.06 & $1.25^{* * *}$ & $1.24^{* * *}$ & $1.11^{+}$ & $1.11^{+}$ & 1.09 & 1.06 \\
\hline Does not like & $1.16^{* * *}$ & $1.31^{* * *}$ & $1.31^{* * *}$ & $1.17^{* * *}$ & $1.17^{* * *}$ & $1.16^{* * *}$ & $1.10^{*}$ \\
\hline Adverse consequences & $1.30^{* *}$ & $1.48^{* * *}$ & $1.47^{* * *}$ & $1.35^{* *}$ & $1.35^{* *}$ & $1.34^{* *}$ & $1.22^{+}$ \\
\hline Loss of control & $1.42^{* * *}$ & $1.61^{* * *}$ & $1.58^{* * *}$ & $1.37^{* *}$ & $1.36^{* *}$ & $1.35^{* *}$ & $1.28^{+}$ \\
\hline Unknown/other & 1.01 & 1.12 & 1.11 & 1.04 & 1.00 & 0.99 & 1.01 \\
\hline Infrequent drinkers & $1.12^{* *}$ & $1.21^{* * *}$ & $1.20 * * *$ & $1.13^{* *}$ & $1.12^{* *}$ & $1.12^{* *}$ & $1.08^{+}$ \\
\hline Former drinkers & $1.33^{* * *}$ & $1.32^{* * *}$ & $1.32^{* * *}$ & $1.25^{* * *}$ & $1.24^{* * *}$ & $1.24^{* * *}$ & $1.16^{* * *}$ \\
\hline \multicolumn{8}{|l|}{ Current drinkers } \\
\hline 1 to less than 2 drinks per day & $1.18^{* *}$ & $1.11 *$ & $1.10^{+}$ & $1.10^{*}$ & $1.10^{*}$ & $1.10^{*}$ & 1.08 \\
\hline 2 to less than 3 drinks per day & $1.63^{* * *}$ & $1.46^{* * *}$ & $1.45^{* * *}$ & $1.45^{* * *}$ & $1.45^{* * *}$ & $1.45^{* * *}$ & $1.44^{* * *}$ \\
\hline 3 or more drinks per day & $2.01^{* * *}$ & $1.67^{* * *}$ & $1.63^{* * *}$ & $1.55^{* * *}$ & $1.55^{* * *}$ & $1.55^{* * *}$ & $1.52^{* * *}$ \\
\hline Sex (male) & $1.48^{* * *}$ & $1.45^{* * *}$ & $1.52^{* * *}$ & $1.52^{* * *}$ & $1.52^{* * *}$ & $1.51^{* * *}$ & $1.54^{* * *}$ \\
\hline \multicolumn{8}{|c|}{ Race/ethnicity (non-Hispanic white) } \\
\hline Non-Hispanic black & $1.23^{* * *}$ & $1.18^{* * *}$ & $1.14^{* *}$ & 1.03 & 1.02 & 1.01 & 1.06 \\
\hline Hispanic & $0.89^{*}$ & $0.88^{*}$ & $0.87^{*}$ & $0.80^{* * *}$ & $0.80^{* * *}$ & $0.80^{* * *}$ & $0.80^{* *}$ \\
\hline Non-Hispanic Asian & $0.56^{* * *}$ & $0.57^{* * *}$ & $0.58^{* * *}$ & $0.57^{* * *}$ & $0.58^{* * *}$ & $0.58 * *$ & $0.69^{+}$ \\
\hline Other & $1.08^{+}$ & 1.06 & 1.05 & 1.03 & 1.03 & 1.03 & 1.05 \\
\hline \multicolumn{8}{|c|}{ Smoking status (never smoked) } \\
\hline Former & & $1.24^{* * *}$ & $1.25^{* * *}$ & $1.24^{* * *}$ & $1.24^{* * *}$ & $1.24^{* * *}$ & $1.20^{* * *}$ \\
\hline Current & & $2.14^{* * *}$ & $2.11^{* * *}$ & $2.05^{* * *}$ & $2.06^{* * *}$ & $2.05^{* * *}$ & $2.09^{* * *}$ \\
\hline \multicolumn{8}{|l|}{ Marital status (married) } \\
\hline Widowed & & & $1.19^{* * *}$ & $1.08 *$ & $1.08^{*}$ & $1.08^{*}$ & $1.09^{*}$ \\
\hline Divorced/separated & & & $1.31^{* * *}$ & $1.18^{* * *}$ & $1.19^{* * *}$ & $1.19^{* * *}$ & $1.25^{* * *}$ \\
\hline Never married & & & $1.29^{* * *}$ & $1.17^{* * *}$ & $1.17^{* * *}$ & $1.18^{* * *}$ & $1.27^{* * *}$ \\
\hline Education & & & & $0.99^{* * *}$ & $0.99^{* *}$ & $0.99^{* *}$ & $0.99^{* *}$ \\
\hline Logged income & & & & $0.85^{* * *}$ & $0.85^{* * *}$ & $0.85^{* * *}$ & $0.89^{* * *}$ \\
\hline BMI & & & & & $0.98^{*}$ & $0.98^{*}$ & 0.99 \\
\hline $\mathrm{BMI}^{2}$ & & & & & $1.00^{* * *}$ & $1.00^{* * *}$ & $1.00^{* *}$ \\
\hline \multicolumn{8}{|l|}{ Region (Northeast) } \\
\hline Midwest & & & & & & $1.06^{+}$ & 1.06 \\
\hline South & & & & & & $1.06^{+}$ & 1.04 \\
\hline West & & & & & & 1.04 & 1.02 \\
\hline
\end{tabular}

${ }^{* * *} p \leq .001 ;{ }^{* *} p \leq .01 ;{ }^{*} p \leq .05 ;{ }^{+} p<.10$

Note: Referent is listed in parentheses. Models control for complex sampling design. $N=41,308$ for Models 1-6. a Model 7 is restricted to respondents who were in good, very good or excellent health at time of interview $(N=35,447)$.

Source: 1988 National Health Interview Survey Alcohol Supplement Linked Mortality File. 


\section{Discussion}

The relationship between the risk of death and drinking status has been understudied by demographers just as the reasons why individuals abstain from drinking have been overlooked by many researchers. Light alcohol consumption can benefit survival, relative to moderate or heavy drinkers, but so can abstention. Individuals who abstain for religious and moral reasons, out of responsibility to their family, because they are not particularly social, or because they were brought up not to drink, have mortality risks that are similar to light drinkers. Interestingly, these low-mortality risk abstainers are more common among non-Hispanic whites, never-smokers, married persons and postgraduates. For example, $46.9 \%$ of postgraduate abstainers are in these categories, compared to $30.3 \%$ of abstainers with less than a high school education (Table 2). Future research could further investigate relationships among social and demographic factors, abstention, health and mortality.

Some lifetime abstainers have higher risks of death than light drinkers, including those who fear the adverse consequences of drinking, fear that they would lose control if they began drinking or dislike the taste of alcohol. Further research could disentangle the underlying social, cultural or genetic (Duffy et al. 2004) reasons that individuals report that they do not care for or dislike the taste of alcohol. This group is disproportionately Hispanic or black, current smokers, divorced, less educated, obese and in the Northeast (Table 2), indicating that there are important influences underlying this response.

Abstainers who have the highest risks of death, relative to light drinkers, might be ill-advised to take up drinking if they have a reasonable concern that they may lose control of their drinking or experience adverse consequences. And individuals who have been exposed to problem drinking in their lives (e.g. by growing up or currently living with a problem drinker), may be acutely aware of the problems associated with excessive drinking and may still be dealing with problems related to drinking among friends or family members. Descriptive statistics for adverse consequences and loss of control (Table 2) also suggest that reports of these reasons vary across groups. Asians report more on adverse consequences but less on loss of control. Older respondents and never-smokers are less likely to report reasons in both of these categories, while low-income respondents are more likely.

Our results complement and extend the results of our parallel study (Rogers et al. 2013). The J-shaped relationship between alcohol consumption and mortality conceals the differences in risk of death among teetotalers. Viewed together, our research makes a strong case for the importance of abstention from drinking in mortality research and suggests the need for further work in determining confounding influences on the alcohol-mortality relationship.

Our analyses adjusted for numerous covariates that might confound the association between drinking and nondrinking statuses and prospective mortality. For example, light drinking may signal that individuals have disposable incomes and are of higher social strata. Our results show that over half of postgraduates but just $23 \%$ of adults with less than a high school degree are current light drinkers (Table 1), and that 
controlling for socio-economic status attenuates the hazard ratios of abstainers (compare Models 3 and 4 in Table 2). Other unmeasured variables, however, may include regular positive social interactions (e.g. socialising after work, at the end of the week and during the weekends), social norms (attitudes about drinking), a zest for life (enjoying good food and drink) and partaking in celebrations (e.g. birthdays, weddings, anniversaries, graduations, sporting events and national holidays).

Although alcohol and mixed drinks contain calories and can contribute to weight gain (Nielsen et al. 2012), we found a negligible effect of body mass on the association between drinking and mortality. Still, some researchers claim that the increased risk of some cancers, including colorectal and breast cancer, may be the result of the excess calories in alcohol rather than alcohol itself (Bonneux 2011). Most likely BMI is but one risk factor, and it may be eclipsed by other factors, including smoking and socio-economic status (see e.g. Miech et al. 2011).

Drinking is also associated with other health behaviours, including the use of licit and illicit drugs, and smoking. For instance, $64 \%$ of current smokers but just $41 \%$ of never-smokers are current drinkers (Table 1). This association between drinking and smoking was evident in the multivariate models, where controlling for smoking status increased the hazard ratios of each abstainer category and attenuated the hazard ratios of each drinking status category (compare Models 1 and 2 in Table 3). And among adult victims of violent death in Colorado, alcohol use was positively correlated with postmortem presence of amphetamines, antidepressants, marijuana, opiates and especially cocaine (Sheehan et al. 2013). Thus, although the 1988 NHIS did not include data on other drug use, we speculate that controlling for other risky behaviours, including other drugs, would be likely to further attenuate the hazard ratios of current, former and infrequent drinkers.

We have detailed many reasons for not drinking. Although it might be difficult to elicit honest answers, it would be fascinating and quite useful to examine the reasons for drinking, either infrequently or regularly. We expect that positive reasons for drinking (such as to socialise and celebrate, because drinking is the norm in the respondent's social circle or because s/he enjoys learning about and drinking fine wines and speciality spirits) would lead to longer lives, and negative reasons (such as drinking to avoid or forget problems, induce sleep, i.e. the 'nightcap', or hide social awkwardness) would result in shorter lives.

The potential survival benefits for some nondrinkers can be contrasted with the substantial risks associated with heavy drinking. Excessive drinking is associated with risky behaviours such as driving under the influence of alcohol; with legal problems, including arrests for public intoxication, drunk driving and violent acts; with social conflict and violence that can disrupt social ties, including relationships with spouses, other family members and friends; and with problems at work, including work absences, reduced productivity, lost promotions and accidents. Moreover, drinking can result in such physical and emotional health problems as vomiting, depression and hallucinations; alcohol withdrawal, finally, can result in delirium tremens.

Our results have important policy implications. Policymakers can increase the benefits and reduce the risks of alcohol consumption by providing current, accurate 
information and education (Anderson et al. 2009; Bonneux 2011). Public policy messages could underscore the mortality risks of heavy alcohol consumption, promote responsible light consumption and note the mortality benefits of abstaining from drinking. Rose asserts that reducing the mean consumption will also reduce the right tail of a distribution: "changes in average consumption will lead to corresponding changes in the prevalence of alcoholism and in alcohol-related health problems" (Rose 2008, p. 121). He shows, for example, that reducing the alcohol intake of all drinkers by $10 \%$ would reduce the numbers of heavy drinkers by onequarter. These changes are consistent with the contagion effect in that individuals are more likely to abstain if their spouses and friends abstain (Rosenquist et al. 2010). Thus, policies that will reduce the mean level of alcohol consumption through encouraging abstention (or light consumption) should in turn lower the percentages of heavy drinkers.

\subsection{Limitations}

Four limitations of our research warrant mention. Our results are based on selfreports. Social desirability bias suggests that some current drinkers may report abstention from drinking or that they are infrequent or former drinkers, and others may underreport their consumption levels. But because alcohol consumption is legal and common, it is unlikely that many drinkers would understate their drinking (see Del Boca and Darkes 2003) — except, of course, for those living in communities that frown on drinking. In any case, it is difficult to obtain nationally representative detailed information on drinking status, including reasons for abstaining, by any other means. The National Health and Nutrition Examination Survey (NHANES) collects biomarker data but has few biomarkers for drinking. There are some biomarkers for excessive drinking and alcoholism although the prevalence of these biomarkers is low. It would be possible to examine blood alcohol levels, only the NHANES does not measure them, however. Besides, blood alcohol levels will vary, depending upon when individuals were drinking and when they have their blood tests, and might not be reliable indicators as we might expect that individuals who knew that they would be getting a blood alcohol test might change their drinking behaviours, or refuse to be tested.

The 1988 NHIS-Alcohol supplement is well suited for our analyses because it includes extra detail on drinking statuses, particularly the reasons why individuals abstain from drinking. But there may be additional reasons that individuals abstain from drinking, and some of the reasons listed may not be fully articulated. For example, individuals who abstain from drinking because a family member is an alcoholic or problem drinker may think that they are predisposed to alcoholism because a parent or sibling is an alcoholic. Alternatively, they may abstain to support a spouse.

The 1988 NHIS-Alcohol also includes a long follow-up of survival status that provides stable estimates of mortality risk. Nevertheless, it would be useful to collect 
similar detailed drinking status measures for newer data sets, including more current NHIS. And because drinking prevalence rates have changed over time and among different subpopulations, it would be worthwhile to replicate our analyses with more recent data. Thus, there are compelling reasons to include similar detailed questions about drinking statuses, including the reasons why individuals abstain from drinking, in future surveys.

We also do not have full information on drinking transitions. Individuals may change their drinking statuses - by starting to drink, increasing their consumption levels or quitting — and these changes will affect the mortality estimates. We know individuals' drinking status only for 1988, not for subsequent years. Furthermore, some individuals, including former and heavy drinkers, would have experienced substantial changes before the interview; heavy drinkers would have slowly increased their consumption, and former drinkers had quit drinking. The left-censoring of individuals below the legal age of 21 should have little effect on our results because the lag between drinking and chronic conditions is long and the strongest effects of alcohol consumption on mortality are at older ages. Thus, future research, especially using longitudinal data, could examine drinking transitions and the risk of death.

\subsection{Future research}

The prospective NHIS-LMF is a rich data set that is well suited for demographic, especially mortality, analyses. The NCHS plans to release new files sometime in the year 2013 that include mortality matches through 2008, which will further expand the reach and improve the power of the NHIS-LMF. Though the NHIS-LMF enables us to produce results that are generalisable to the United States and similar populations, alcohol consumption varies substantially by country. Compared to the United States, adult alcohol consumption per capita is higher in many European countries, including France, Germany, the Netherlands and the United Kingdom, but it is lower in many Asian countries, including India, Indonesia and China, and many Latin American countries, including Brazil, Chile and Mexico (Himes 2011). Because legal drinking ages, drinking prevalence rates and consumption levels vary by country, it would be informative to replicate our analysis for other countries. Moreover, to allow accurate international comparisons, it is of paramount importance to produce more harmonised datasets, that is, datasets that ascertain the same information collected with similar methods over the same periods.

\section{Conclusion}

We have demonstrated the important association between alcohol consumption and mortality, and the importance of considering the relationship between reasons for abstention and mortality. We find similar mortality risks among light drinkers and individuals who abstain for religious or moral reasons, out of family responsibility, 
or because they are not social. Thus, the route to long lives can be realised through either light drinking or abstention. Our results should contribute to the betterment of the general population of the United States and other countries.

\section{Acknowledgments}

We thank the Eunice Kennedy Shriver NICHD-funded University of Colorado Population Center (grant R24 HD066613) for administrative and computing support; the National Center for Health Statistics (NCHS) for collecting the data and making the linked files available to the research public; and Nancy Mann for editorial assistance. An earlier version of this manuscript was presented at the Determinants of Unusual and Differential Longevity International Conference, Vienna, Austria, November 21-23, 2012. The content of this manuscript is solely the responsibility of the authors and does not necessarily represent the official views of NIH, NICHD or NCHS.

\section{References}

Agarwal, D. P. 2002. "Cardioprotective Effects of Light-Moderate Consumption of Alcohol: A Review of Putative Mechanisms". Alcohol and Alcoholism 37 (5): 409-415. doi:10.1093/alcalc/37.5.409.

Allison, P. D. 2002. Missing Data. Thousand Oaks, CA: Sage.

Anderson, P., D. Chisholm, and D. C. Fuhr. 2009. "Effectiveness and CostEffectiveness of Policies and Programmes to Reduce the Harm Caused by Alcohol". The Lancet 373 (9682): 2234-2246. doi:10 . 1016/S0140-6736 (09)60744-3.

Andreasson, S. 1998. "Alcohol and J-Shaped Curves". Alcoholism: Clinical and Experimental Research 22 (7): 359-364. doi:10 . 1111/ j . 1530-0277 . 1998. tb04391. $\mathrm{x}$.

Beaglehole, R., and R. Jackson. 1992. "Alcohol, Cardiovascular Diseases and All Causes of Death: A Review of the Epidemiological Evidence". Drug and Alcohol Review 11 (3): 275-290.

Bernards, S., K. Graham, H. Kuendig, S. Hettige, and I. Obot. 2009. "I Have No Interest in Drinking: A Cross-National Comparison of Reasons Why Men and Women Abstain From Alcohol Use". Addiction 104 (10): 1658-1668. doi:10 . 1111/j.1360-0443.2009.02667.x.

Blocker, J. S. J. 2006. "Did Prohibition Really Work? Alcohol Prohibition as a Public Health Innovation”. American Journal of Public Health 96 (2): 233-243. doi:10.2105/AJPH. 2005.065409. 
Bonneux, L. 2011. "Mortality Affected by Health Care and Public Health Policy Interventions". In International Handbook of Adult Mortality, ed. by R. G. Rogers and E. M. Crimmins, 583-607. International Handbooks of Population 2. New York: Springer.

Campbell, C. A., R. A. Hahn, R. Elder, R. Brewer, S. Chattopadhyay, J. Fielding, T. S. Naimi, T. Toomey, B. Lawrence, J. C. Middleton, and Task Force on Community Preventive Services. 2009. "The Effectiveness of Limiting Alcohol Outlet Density as a Means of Reducing Excessive Alcohol Consumption and Alcohol-Related Harms". American Journal of Preventive Medicine 37 (2): 556-569. doi:10.1016/j . amepre.2009.09.028.

Centers for Disease Control and Prevention (CDC). 2013. Alcohol Use and Health: Fact Sheets. http : / / www . cdc . gov / alcohol / fact - sheets / alcohol use.htm.

Del Boca, F. K., and J. Darkes. 2003. "The Validity of Self-Reports of Alcohol Consumption: State of the Science and Challenges for Research". Addiction 98 (2): 1-12. doi:10.1046/j.1359-6357.2003.00586.x.

Doll, R., R. Peto, E. Hall, K. Wheatley, and R. Gray. 1994. "Mortality in Relation to Consumption of Alcohol: 13 Years' Observations on Male British Doctors". British Medical Journal 309 (6959): 911-918.

Duffy, V. B., J. M. Peterson, and L. M. Bartoshuk. 2004. "Associations Between Taste Genetics, Oral Sensation and Alcohol Intake". Physiology \& Behavior 82 (2): 435-445. doi:10.1016/j . physbeh. 2004.04.060.

Epler, A. J., K. J. Sher, and T. M. Piasecki. 2009. "Reasons for Abstaining or Limiting Drinking: A Developmental Perspective". Psychology of Addictive Behaviors 23 (3): 428-442. doi:10.1037/a0015879.

Falk, D. E., H. Y. Yi, and S. Hiller-Sturmhofel. 2006. "Findings From the National Epidemiological Survey on Alcohol and Related Conditions". Alcohol Research $\mathcal{E}$ Health 29 (3): 162-171.

Fillmore, K. M., W. C. Kerr, T. Stockwell, T. Chikritzhs, and A. Bostrom. 2006. "Moderate Alcohol Use and Reduced Mortality Risk: Systematic Error in Prospective Studies". Addiction Research E Theory 14 (2): 101-132. doi:10. 1080/16066350500497983.

Graham, K. 1998. "Alcohol Abstention Among Older Adults: Reasons for Abstaining and Characteristics of Abstainers". Addiction Research 6 (6): 473-487.

Hilton, M. E. 1998. "Abstention in the General Population of the U.S.A.” British Journal of Addiction 81 (1): 95-112. doi:10 . $1111 / \mathrm{j} .1360$ - 0443 . 1986 . tb00300.x.

Himes, C. L. 2011. "Relationships Among Health Behaviors, Health, and Mortality". In International Handbook of Adult Mortality, ed. by R. G. Rogers and E. M. Crimmins, 289-310. International Handbooks of Population 2. New York: Springer. 
Jylhä, M. 2011. "Self-Rated Health and Subjective Survival Probabilities as Predictors of Mortality". In International Handbook of Adult Mortality, ed. by R. G. Rogers and E. M. Crimmins, 329-344. New York: Springer.

Klatsky, A. L. 2001. "Commentary: Could Abstinence From Alcohol Be Hazardous to Your Health?" International Journal of Epidemiology 30 (4): 739-742. doi:10. $1093 / \mathrm{ije} / 30.4 .739$.

Liang, W., and T. Chikritzhs. 2010. "Reduction in Alcohol Consumption and Health Status". Addiction 106 (1): 75-81. doi:10.1111/j .1360-0443.2010.03164.x.

Lourenço, S., A. Oliveira, and C. Lopes. 2012. "The Effect of Current and Lifetime Alcohol Consumption on Overall and Central Obesity". European Journal of Clinical Nutrition 66 (7): 813-818. doi:10.1038/ejcn.2012.20.

Massey, J. T., T. F. Moore, V. L. Parsons, and W. Tadros. 1989. "Design and Estimation for the National Health Interview Survey, 1985-94". Vital and Health Statistics 2 (110): 1-33.

Miech, R., F. Pampel, J. Kim, and R. G. Rogers. 2011. "The Enduring Association Between Education and Mortality: The Role of Widening and Narrowing Disparities". American Sociological Review 76 (6): 913-934. doi:10 . 1177 / 0003122411411276.

Mokdad, A. H., J. S. Marks, S. D. F., and G. J. L. 2004. "Actual Causes of Death in the United States, 2000". Journal of the American Medical Association 291 (10): 1238-1245. doi:10.1001/jama.291.10.1238.

Nielsen, S. J., B. K. Kit, T. Fakhouri, and C. L. Ogden. 2012. Calories Consumed From Alcoholic Beverages by U.S. Adults, 2007-2010. http://www.cdc.gov/ nchs/data/databriefs/db110.pdf.

Poulain, M., A. Herm, and G. Pes. 2012. The Blue Zones: Areas of Exceptional Longevity Around the World. Presented at Determinants of Unusual and Differential Longevity International Conference, Vienna, 21-23 November 2012.

Rehm, J., D. Baliunas, G. L. G. Borges, K. Graham, H. Irving, T. Kehoe, C. D. Parry, J. Patra, S. Popova, V. Poznyak, M. Roerecke, R. Room, A. V. Samokhvalov, and B. Taylor. 2010. "The Relation Between Different Dimensions of Alcohol Consumption and Burden of Disease: An Overview". Addiction 105 (5): 817-843. doi:10.1111/j.1360-0443.2010.02899.x.

Rogers, R. G., P. M. Krueger, R. Miech, E. M. Lawrence, and R. Kemp. 2013. "Nondrinker Mortality Risk in the United States". Population Research and Policy Review 32 (3): 325-352. Forthcoming. doi:10. 1007/s11113-013-9268-7.

Rose, G. 2008. Rose's Strategy of Preventive Medicine: The Complete Original Text. With a comment. by K. K and M. Marmot. Oxford: Oxford University Press.

Rosenquist, J. N., J. Murabito, J. H. Fowler, and N. A. Christakis. 2010. "The Spread of Alcohol Consumption Behavior in a Large Social Network". Annals of Internal Medicine 152 (7): 426-433. doi:10 . 7326/0003-4819-152-7-20100406000007. 
Schiller, J. S., J. W. Lucas, and J. A. Peregoy. 2012. "Summary Health Statistics for US Adults: National Health Interview Survey, 2011". Vital and Health Statistics 10 (256): 1-219.

Shaper, A. G., G. Wannamethee, and M. Walker. 1988. "Alcohol And Mortality In British Men: Explaining the U-Shaped Curve". The Lancet 2 (8623): 1267-1273. doi:10. 1016/S0140-6736(88)92890-5.

Sheehan, C. M., R. G. Rogers, G. W. Williams, and J. D. Boardman. 2013. "Gender Differences in the Presence of Drugs in Violent Deaths". Addiction 108 (3): 547-555. Forthcoming. doi:10.1111/j . 1360-0443.2012.04098 . x.

StataCorp. 2011. Stata Statistical Software: Release 12. Comp. software. College Station, TX.

U.S. Department of Agriculture (USDA) and U.S. Department of Health and Human Services (USDHHS). 2010. Dietary Guidelines for Americans, 2010. Seventh edition. Washington, DC: U.S. Government Printing Office. http://www . health. gov/dietaryguidelines/dga2010/DietaryGuidelines2010.pdf.

Wannamethee, S. G., and A. G. Shaper. 1997. "Lifelong Teetotallers, Ex-Drinkers and Drinkers: Mortality and the Incidence of Major Coronary Heart Disease Events in Middle-Aged British Men”. International Journal of Epidemiology 26 (3): 523-531. doi:10.1093/ije/26.3.523. 